\title{
GIS Based Analysis of Interaction between Port Accessibility and Economy in Saudi Arabia
}

\author{
Amin S. Hamdi \\ Department of Civil Engineering, King Abdulaziz University, Jeddah 21589, Saudi Arabia \\ ahamdi@kau.edu.sa
}

\begin{abstract}
Land transportation networks play key role in economic activities by providing access to industries and commercial centers. As integral part of transportation system ports provide essential interchange between sea and land communication to facilitate interaction with global economic hubs. Region's accessibility to port usually determines its production and growth potential. This paper provides quantitative analysis of roadway based port accessibility to different regions in Saudi Arabia using GIS framework. It also provides analytical basis for comparing relative geographical implications of the ports in the context of regional GDP and population concentration. Using geoprocessing tools like Network Analyst and Spatial Analyst in ArcGIS framework, accessibility contours are assessed. Then spatial indicators are developed to measure interaction between accessibility and economic parameters. Using these indicators, the regions lacking in adequate port accessibility are identified. Further analysis reveals that investment to improve accessibility of these regions may provide beneficial effect on their economic growth. The proposed procedure may be applied in regional planning and economic feasibility studies.
\end{abstract}

Keywords: Port, Accessibility, Economy, GIS, Network.

\section{Introduction}

Efficient accessibility is considered as essential input in socio-economic development. Access to input resources and output markets determine production potential and investment opportunities for products and services. Transportation networks, in the form of roadway, railway, waterway and airways, provide the links and nodes for facilitating accessibility. Intermodal transfer nodes, like ports and terminals, are major determinants in accessibility provision that is particularly important for freight distribution. Suitable access to the transfer node is essential for economic and demographic expansion of any region to facilitate regional and global access to inputs and markets. Assessing economic impact of region's accessibility to port and its interaction with production factors is a challenging research issue in transport economics and regional planning. Issues of particular interest in this regard include the approaches for accessibility measurement and frameworks for assessing its interaction with regional socioeconomic indicators. Core concerns underlying the analytical challenge comprise difficulties in specification of accessibility, measurement of spatial and temporal impedances among the entities of interest, and formulation of functional form of interaction with socioeconomic indicators. 
Although capital, land, and labor are primary ingredients for production units such as industries or regions, transportation infrastructure is a necessary prerequisite input resource in economic activities ${ }^{[1-2]}$. Filip and Popa [3] observe that the investment in transportation is an effective tool for regional development, particularly in developing countries. They suggest that development of the transport system causes expansion and intensification of production, and facilitate circulation of goods. Button and Reggiani ${ }^{[4]}$ noticed that although in general economic growth is linked to transport development, regional discrepancy in accessibility provision may be harmful. They noted that although some regions may reap benefits from transport system development, others are often marginalized by inadequate development of properly transport system. Alam et al. [5] demonstrate that transportation is an essential component in economic activity that critically affects production efficiency of any region. Ozbay et al. ${ }^{[6]}$ identify strong and significant relationships between accessibility changes and economic development using production function based on the conceptual framework that production units need flow of input resources and access to the markets for being functional. Seskin et al. ${ }^{[7]}$ and Berechman et al. [8] provide an extensive review of econometric and statistical models used to analyze the role of transportation infrastructure development in economic expansion. Limani ${ }^{[9]}$ and Rodrigue ${ }^{[10]}$ suggest that while in some regions transport acts as facilitator of economic growth, in other regions economic progress may induce investment in infrastructure development. Authors recommend use of exante and ex-post techniques to assess precise correlations.

Within transportation infrastructure, ports and terminals are highly important intermodal interchanges for import and export of input raw materials and output products. Spatial impact of ports, that facilitates commodity flow between external and internal production entities, deserves especial research attention. Dwarakisha and Salim ${ }^{[11]}$ critically review the role of port infrastructure on economy of various countries. They demonstrate that, in general, port development leads to enhanced trade activity, increased supply, and reduced prices for commodities. Lagneaux [12] analyzes socio-economic importance of Belgian ports with indicators such as value added, employment and investment using input-output framework. The author suggests that distribution of ports in the context of national geographic layout and industrial locations requires extensive analysis in order to identify potential regions for future development. Cullinane and Yuhong ${ }^{[13]}$, and Yuhong and Cullinane [14] present methodology for analyzing port accessibility and its interaction with port performance. Jung [15] shows that there exists a reciprocal relationship between regional economy and port accessibility, and to be more effective in regional economic development ports need to integrate into global supply chain.

In the context of Saudi Arabia's vision for industrialization and economic development, the role of transportation network and access to ports are highly significant to facilitate unconstrained imports and exports of raw materials, machineries and products. To ensure equity in economic development, adequate access to transport network and ports for all the regions should be provided. Accordingly, the assessment of zonal accessibility needs and evaluation of discrepancies in zonal infrastructural endowments may assist the planners to identify zones with lagging accessibility, and may be beneficial in policy formulation for regional infrastructure development. With this perspective, the research work reported in this 
paper focuses on analyzing port accessibility of different regions in Saudi Arabia considering their socio-economic parameters.

Measurement of accessibility is one of the key elements in analysis of regional economic impact of ports. Access is multifaceted and complex concept that is dependent on the characteristics of both the entity of interest and connectivity network system. Litman ${ }^{[16]}$ recognizes accessibility as the most effective tool for reflecting the ultimate goal of transportation and suggests that it is difficult to measure as it can be affected by many factors. He recommends the use of activity based travel models and integrated transport-landuse models for quantifying accessibility. El-Geneidy and Levinson [17] elaborately explain the significance of accessibility and available approaches for its measurement. Goulias [18] summarizes different methodologies for analyzing accessibility and its measurement using GIS. Spiekerman and Wegener [19] propose measurement of accessibility on the basis of either Euclidian distance or Network Distance. Miller ${ }^{[20]}$, Handy and Niemeier ${ }^{[21]}$, and Kwan ${ }^{[22]}$ recognize that accessibility is one of the most elusive concepts in transport planning and modeling. Authors acknowledge that both the parameter and functional specification of accessibility measurement is challenging. From extensive literature review they found that a combination of travel impedance (distance/time) and attractiveness (desire for/opportunity of interaction) are used to variable parameterization, and inverse polynomial and random utility log-sum are usually applied as functional form in accessibility measurement. Yoshida and Deichmann [23] endorsed Geographic Information System (GIS) as one of the most effective tools for accessibility analysis.

This paper focuses on analyzing relationship of roadway based port accessibility with regional GDP and population distribution for Saudi Arabia using geographic information system (GIS). It analyzes roadway connectivity to different regions of the country from its major international ports using network connectivity analysis procedure in ArcGIS. Analytical approaches for this purpose involve creating road impedance raster, based on road network vectors with ports as the point of interest, which is then inversed to obtain a measure of accessibility. Population and GDP raster maps are also developed by interpolating the data for thirty-six cities in the country. Then all the three raster maps are normalized into four levels through reclassification technique to facilitate uniform comparison. Resulting normalized raster are then compared using raster algebra available in ArcGIS tools. After the introduction, Section 2 of the paper covers data collection and analytical methods applied in the research. Section 3 presents the results of the analysis and discussion on their implications on reginal planning. Finally, Section 4 summarizes the findings of the research.

\section{Data and Methods}

\subsection{Economic and Transport Network Data of Saudi Arabia}

Analysis reported in the paper is based on geographic locations of ports in Saudi Arabia, database of regional GDP and demography of the country, and spatial roadway connectivity between ports and regions. Both network and raster-based methods of measuring accessibility among locations depend upon detailed and accurate representation of roadway layout and port locations. Recent regional map of Saudi Arabia (Fig. 1) and its road network vector (year 2014) are obtained from the General Commission for Survey, Saudi Arabia (www.gcs.gov.sa). Socio-economic and 
demographic data is collected from Central Department of Statistics and Information, and national census reports ${ }^{[24-25]}$. Information extracted from the database includes population and GDP of the major cities of Saudi Arabia and corresponding functional areas.

\subsection{Accessibility Measurement Methods}

Decision makers and planners frequently face the challenge of determining adequate amount of investment for transport infrastructure to ensure economic development. Measurement of infrastructural need for this purpose is a classical research issue. Due to ever increasing resource constraints and competition, there has been phenomenal growth in research on the measurement of accessibility in recent years [16-23]. In general, accessibility refers to the ability to reach opportunities with least impedance. The different types of conceptual frameworks developed to measure relative impedance are briefly summarized below.

a) Distance based approach: Using inverse remoteness function as impedance where remoteness can be measured either as Euclidian or as network distance.

b) Cost based approach: Using inverse of travel cost function as impedance where cost incorporates network condition and congestion effect.

General functional form of accessibility of region $i$ is given by the following Equation (1):

$$
A_{i}=f\left(\sum_{\forall j} \frac{1}{G C_{i j}}\right)
$$

Where, $\mathrm{GC}_{i j}$ is the generalized cost or impedance between zones $i$ and $j$.

In this study, inverse of the network distance between the regional centroids, which are represented by the major cities in Saudi
Arabia, and the ports are used as the impedance measure of port accessibility.

\subsection{Analytical Framework in GIS}

GIS technology is a useful tool for analyzing spatial interaction between economic entities. Ortega ${ }^{[26]}$ applies GIS for analyzing impact of transportation infrastructure at different geographic levels varying from local to regional extent. The analytical approach is extended in this paper to explore the relationship of port accessibility with economic indicators like GDP and population concentrations. The methodology is structured into three stages.

The first stage involves development of accurate GIS map for port locations, road network and regional socioeconomic indicators. Port locations are incorporated into GIS map of Saudi Arabia as point shape file based on their geographic coordinates obtained from Saudi Ports Authority website (www.ports.gov.sa). Road network line shape file is created on the basis of maps provided by the Ministry of Transport of Saudi Arabia (www.mot.gov.sa). Socioeconomic information of thirty-six major cities of Saudi Arabia, as obtained from Central Department of Statistics and Information (www.cdsi.gov.sa) and Annual Statistical Yearbook ${ }^{[25]}$, is incorporated as point shape file in ArcGIS maps.

The second stage of analysis incorporates conversion of the different shape files into uniform framework for comparison and manipulation. Initially road network vector shape file is converted into raster road map. In the paper, accessibility is defined as inverse of network distance among the regions. To measure regional accessibility the cost distance raster network is initially created using ports as the source input feature and raster road map as cost path. The output cost distance raster is then converted into port 
accessibility raster through raster inversing process. Figure 2 shows link based port accessibility raster map for Saudi Arabia.

Link based accessibility raster is then converted into cost contour raster surface through interpolation that is later classified into four accessibility classes as shown in Fig. 3. The figure shows that accessibility for the regions near port areas are higher than the central and peripheral regions.

The third stage of the analysis involves development of raster maps for economic and demographic information. As mentioned earlier that GDP and population information for thirty-six major cities across Saudi Arabia is incorporated into GIS map. Then the contour surface raster maps for GDP and population density are created using interpolation which are shown in Fig. 4 and 5 respectively. GDP is comparatively higher in Riyadh, Jeddah and Dhahran region and, population concentration is relatively higher in Riyadh, Jeddah, Mekkah and Medinah region. To facilitate comparative analysis, all the raster maps are then normalized using following equation and classified into four levels as shown in Fig. 6.

Normalized Value

$=($ Raster Value - Min.Value $) /($ Max.Value - Min.Value $)$
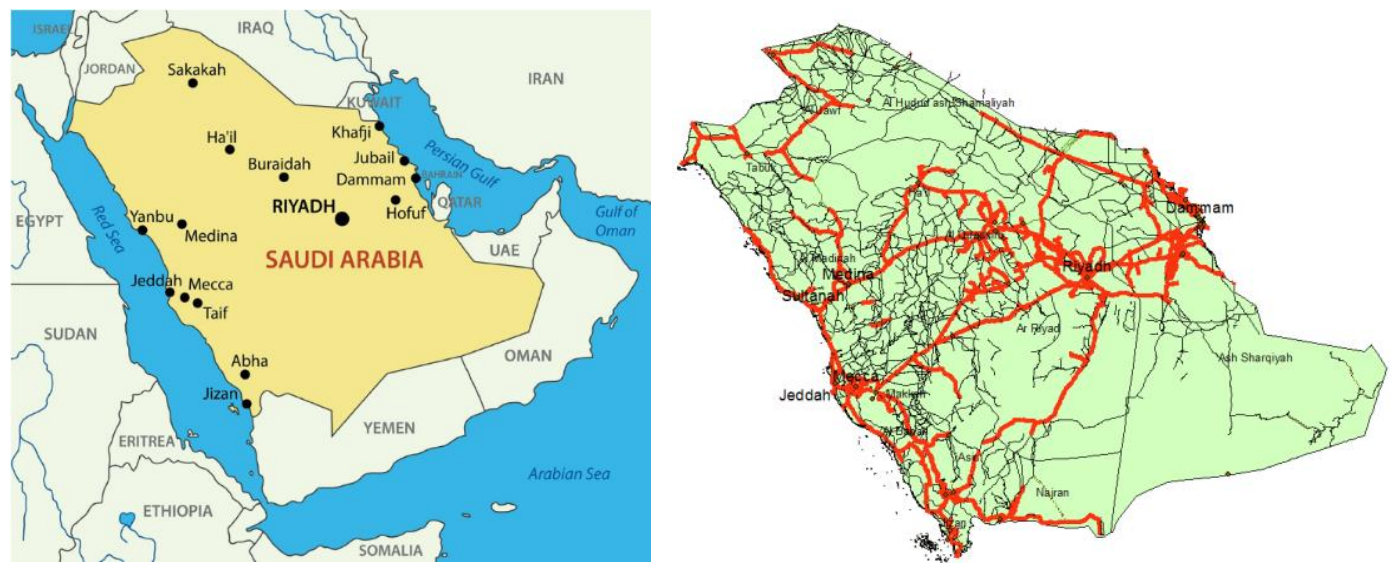

Fig. 1. Map of Saudi Arabia and its Road Network.

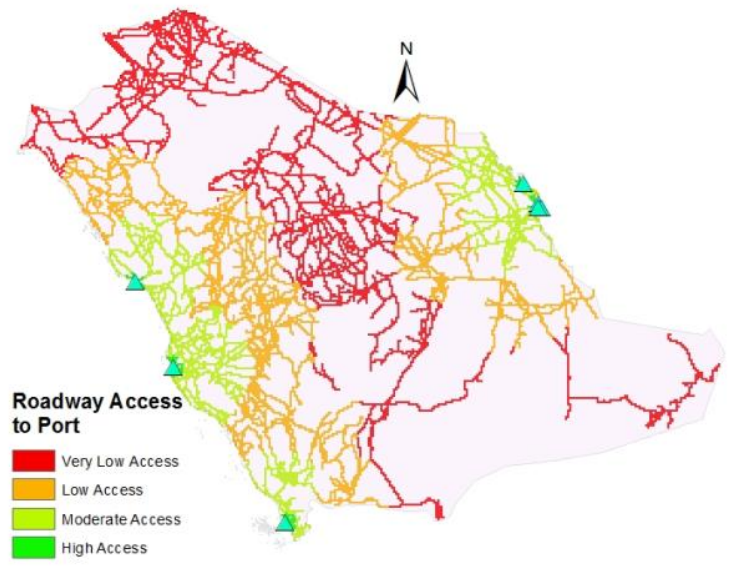

Roadway Accessibility to Port for Different Regions in Saudi Arabia

Fig. 2. Port Accessibility Raster Map of Saudi Arabia. 


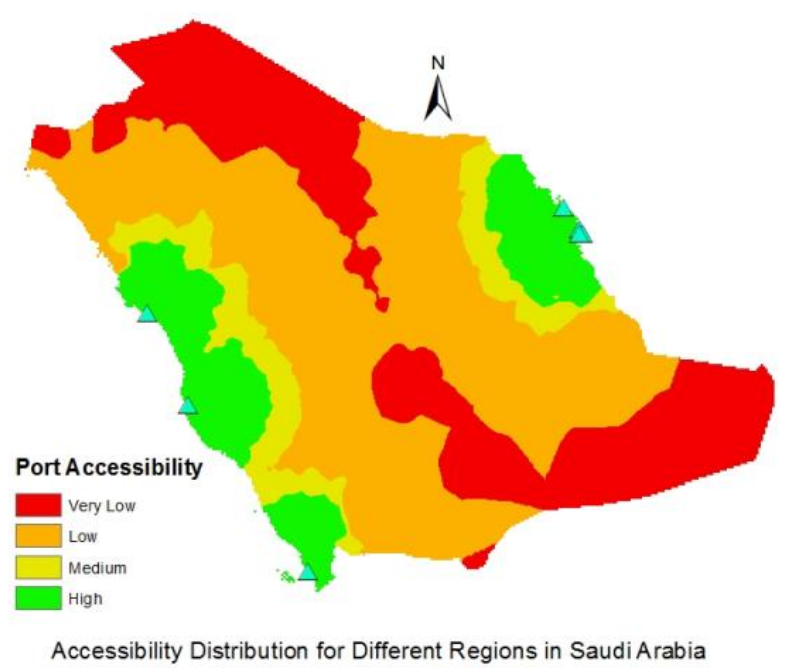

Fig. 3. Port Accessibility Raster Contour Map of Saudi Arabia.

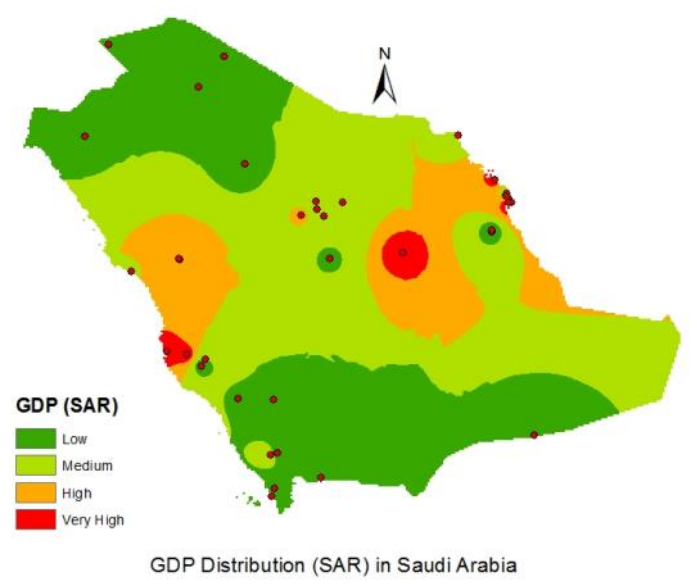

Fig. 4. GDP Distribution Contour of Saudi Arabia.

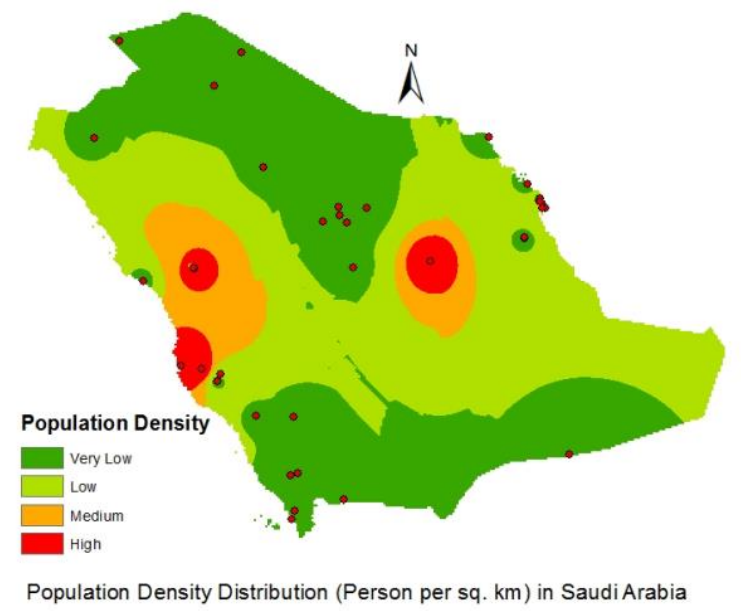

Fig. 5. Population Density Distribution Contour Map of Saudi Arabia. 

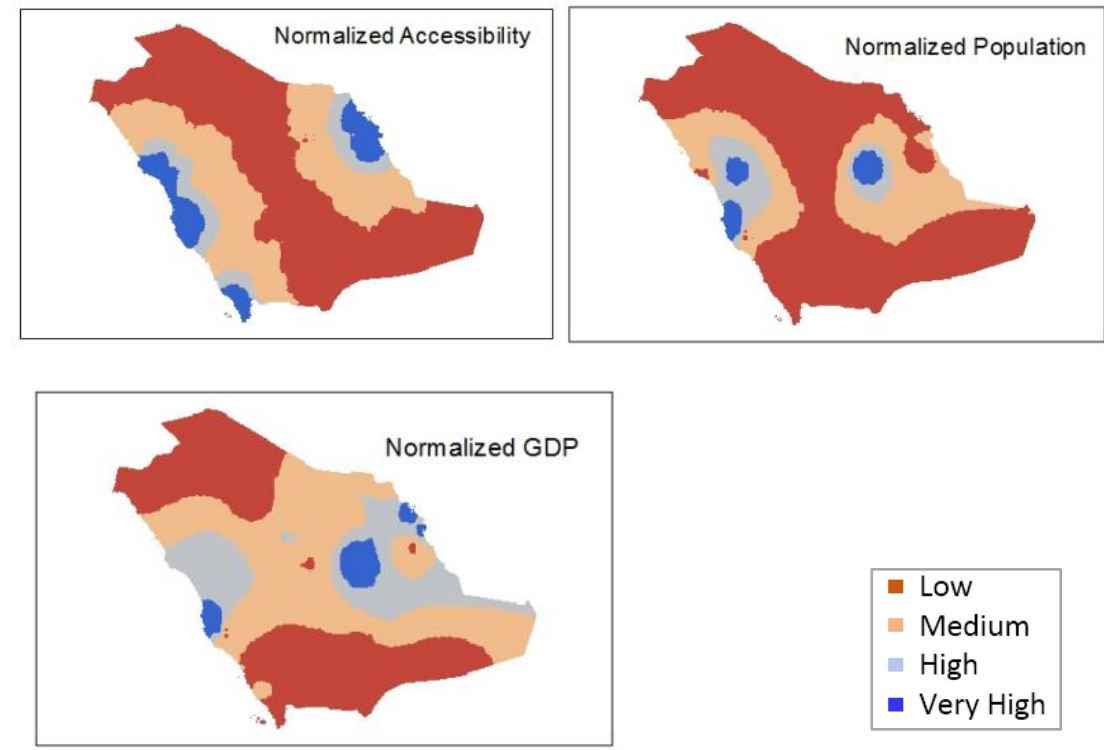

Fig. 6. Normalized Accessibility, Population Density and GDP Distribution Raster Contour Maps of Saudi Arabia.

\section{Results and Discussion}

Effect of port accessibility on economy and population density is measured by comparing the normalized maps using raster algebra in ArcGIS. Firstly, association of normalized accessibility with GDP and population concentration is evaluated using correlation analysis. The coefficient of correlation of normalized regional accessibility (NRA) with normalized GDP (NGDP) and normalized population density (NPD) is 0.72 and 0.79 , respectively. High correlation coefficient implies significant dependency of GDP and population concentration on transport network connectivity to the ports. Spatial regression also demonstrates strong relationship among the variables as shown in the following Equations (2\&3).

$$
\begin{aligned}
& N G D P=0.06+0.86 N R A \quad\left(R^{2}=0.75\right) \\
& N P D=0.11+0.89 N R A \quad\left(R^{2}=0.81\right)
\end{aligned}
$$

The difference of normalized regional accessibility to normalized GDP and population density provides insight into spatial distribution of the parameters as explained below. The small difference between normalized accessibility and normalized GDP or population density implies that infrastructure provision is proportionate with the demand of economic activities. Surplus or shortage of transport infrastructure is indicated by positive or negative value of the difference respectively which is presented in the expressions below.

NRA-NGDP $=0$ or NRA-NPD $=0$ imply balanced scenario.

NRA-NGDP $>0$ or NRA-NPD $>0$ imply accessibility dominant scenario.

NRA-NGDP $<0$ or NRA-NPD $<0$ imply poor accessibility scenario.

Relative differences of accessibility levels with GDP and population density levels are shown in Fig. 7(a) \& 7(b) respectively. Analysis on the basis of GDP shows that in the central region (that include Riyadh) GDP is relatively higher with respect to accessibility level. In Jeddah and Dhahran region, both accessibility and GDP are high. On the contrary, in the northern and southern regions both accessibility and GDP are low although they are balanced as they belong to the same 
level in either metric. In the case of population, central region (particularly Riyadh) has much higher population density level compared to port accessibility level. In the case of Jeddah both population density and accessibility are in balanced condition with high levels in both metrics. Conversely, in northern, southern and a part of the central region the scenario is balanced with low level in both accessibility and population density metrics.

Results suggest that in the context of Saudi Arabia, except for Riyadh region, both population concentration and economic activity is closely related to port accessibility. There exist opportunities for economic development, particularly in the areas with low accessibility, by improving connectivity to the ports. Enhancement of connectivity to ports through improvement of transportation

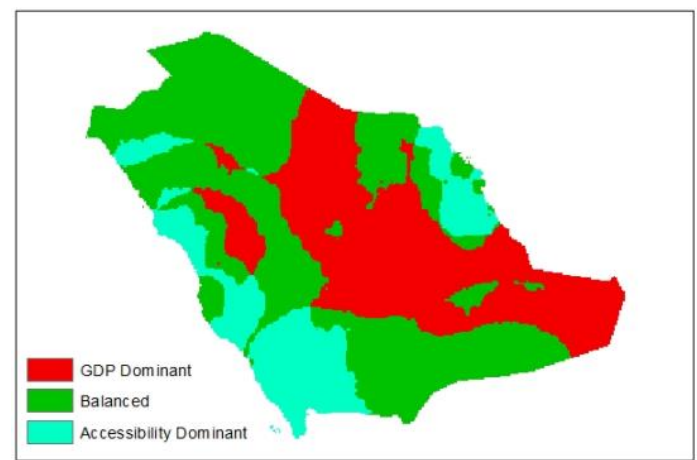

Fig. 7(a). Raster Difference between Port Accessibility and GDP.

\section{Conclusion}

Based on spatial analysis methods, using ArcGIS Engine components, we built different normalized indices to evaluate regional accessibility of ports in Saudi Arabia. The analyses revealed positive correlation of port accessibility with regional GDP and population concentration for all the regions of infrastructure may be particularly beneficial to the northern and southern zones where both accessibility and GDP are in low level. Accessibility to port for these zones is significantly poor. Improvement of access to these zones has potential of inducing significant contribution in national economy. Enhancement of accessibility through development of other modes like high-speed railway connectivity will also produce similar positive impact.

Equations 2 and 3 represent linear functional dependencies of GDP/Population on accessibility. As the variables are normalized, coefficients of the independent variables in these equations will provide estimates of elasticity. From the equations we can conclude that elasticity of GDP growth with respect to accessibility is 0.86 .

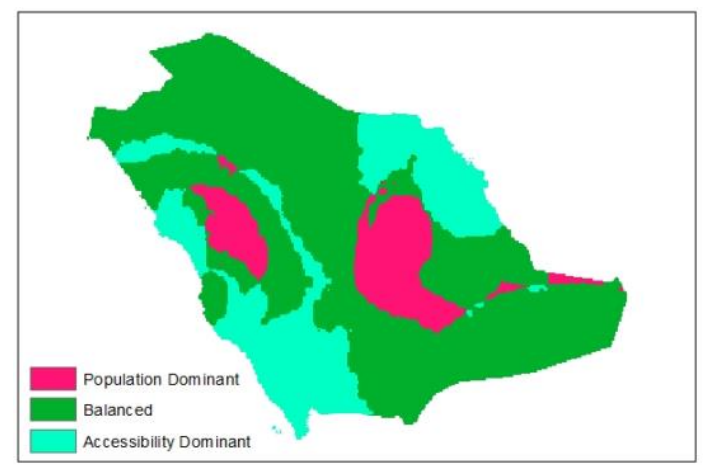

Fig. 7(b). Raster Difference between Port Accessibility and Pop. Density.

the country except Riyadh. Elasticity of GDP growth for accessibility enhancement is 0.86 implying that one percent increase in accessibility to port will result in 0.86 percent growth in regional GDP. We also identified the regions in the country having low accessibility to the ports and recommended for their economic expansion through improvement in accessibility. Findings of this 
study can provide directives for future infrastructure policy development and investment in the following ways.

i) Port accessibility for the northern and southern zones need to be enhanced in order to utilize their economic potential. In these zones infrastructure investment may induce economic growth.

ii) For regions like Jeddah and Dammam, port accessibility and economic activity is in balanced situation. But, for new industrial developments and economic expansion further investment in infrastructure development will be required.

iii) For the regions with adequate port accessibility (like Yanbu, Abha, Dammam, ... etc.) industrial investment opportunities should be explored to grasp the advantages provided by surplus accessibility conditions.

The methodology described in this paper can be used for other transportation infrastructure like airports and intermodal container stations as well as for different industrial sectors. Furthermore, the methodology can be extended to analyze the relative impact of future developments of transport systems like improvements in regional high-speed rail network and expansion of national highways.

\section{References}

[1] Boomgaard, P. (2005), Labour, Land, and Capital in Pre-Modern and Early-Modern Southeast Asia, The Rise, Organization and Institutional Framework of Factor Markets, Conf. of Global Economic History Network, Utrecht, Netherlands.

[2] Keeling, M. and Mooney, G.M. (2011) Transportation and economic development, Executive Report, IBM Global Business Services of IBM Institute for Business Value, IBM Corporation, USA.

[3] Filip, N. and Popa, C. (2014), The Role of Transportation in Economic Development, Naval Academy Scientific Bulletin, XVII(2) Constanta,
Romania.

[4] Button, K. and Reggiani, A. (2011), Transportation and Economic Development Challenges, Edward Elgar Publishing, Cheltenham.

[5] Alam, J.B., Sikder, S.H. and Goulias, K.G. (2005), On the Role of Transportation in Regional Economic Efficiency in Bangladesh: A Data Envelopment Analysis, TRB 06/2004; TRR(1864):112-120. DOI: 10.3141/1864-15.

[6] Ozbay, K., Ozmen-Ertekin, D. and Berechman, J. (2003), Empirical Analysis of Relationship between Accessibility and Economic Development. J. Urban Plann. Dev., 10.1061/(ASCE)0733-9488(2003) 129: 2 (97), 97-119.

[7] Seskin, S.N. (1990), Comprehensive Framework for Highway Economic Impact Assessment: Methods and Results, Transportation Research Record, 1274: 24-34.

[8] Berechman, J., Ozmen, D. and Ozbay, K. (2006), Empirical analysis of transportation investment and economic development at state, county and municipality levels. Transportation, 10.1007/s11116006-7472-6, 537-551.

[9] Limani, Y. (2016), Applied Relationship between Transport and Economy, Proceedings of 17th IFAC Conference on Technology, Culture and International Stability, Albania, Elsevier.

[10] Rodrigue, Jean-Paul (2013). The Geography of Transport Systems. Routledge, New York.

[11] Dwarakisha, G.S. and Salim, A.M. (2015), Review on the Role of Ports in the Development of a Nation, International Conference on Water Resources, Coastal and Ocean Engineering (ICWRCOE 2015), Aquatic Procedia 4: 295 - 301.

[12] Lagneaux F. (2004), Economic importance of the Flemish maritime ports: Report 2002, Document Series, National Bank of Belgium, Brussels.

[13] Cullinane, K. and Yuhong, W. (2009), A capacitybased measure of container port accessibility, International Journal of Logistics 04/09; 12(2): 103117 DOI:10.1080/13675560902749340.

[14] Yuhong W. and Cullinane, K. (2008), Measuring Container Port Accessibility: An Application of the Principal Eigenvector Method (PEM), Maritime Economics \& Logistics, 10: 75-89. doi: 10.1057/ palgrave.mel.9100192.

[15] Jung, B. (2011), Economic Contribution of Ports to the Local Economies in Korea, The Asian Journal of Shipping and Logistics, 27(1): 1-30.

[16] Litman, T. (2011), Measuring Transportation Traffic, Mobility and Accessibility, ITE Journal, 73 (10): $28-32$ 
[17] El-Geneidy, A.M. and Levinson, D.M. (2006), Access to Destinations: Development of Accessibility Measures, Final Report 2006-16. Minnesota Dept. of Transp., USA.

[18] Goulias, K.G. (2007), An optimal resource allocation tool for urban development using GISbased accessibility measures and stochastic frontier analysis, PATH research report, UCB-ITS-PRR2007-7, California PATH Program, Institute of Transportation Studies, University of California at Berkeley, USA.

[19] Spiekerman, K. and Wegener, M. (1996), TransEuropean networks and unequal accessibility in Europe. European Journal of Regional Development (EUREG), 4/96: 35-40.

[20] Mller, E.J. (2018), Accessibility: measurement and application in transportation planning, Transport Reviews, 38: 5, 551-555, DOI: 10.1080/01441647. 2018.1492778.

[21] Handy, S.L. and Niemeier, D.A. (1997), Measuring accessibility: An exploration of issues and alternatives, Environmental Planning A, 29 (7): 1175-1184.
[22] Kwan, M.P. (1998), Space-time and integral measures of individual accessibility: A comparative analysis using a point-based framework. Geographical Analysis, 30(3): 191-216.

[23] Yoshida, N. and Deichmann, U. (2009), Measurement of Accessibility and Its Applications, Journal of Infrastructure Development, 1(1): 1-16, SAGE Publications, DOI: 10.1177/ 097493060900100102.

[24] Annual Statistical Yearbook (2014), Central Department of Statistics and Information, Kingdom of Saudi Arabia.

[25] Population and Housing Census (2010), Kingdom of Saudi Arabia Riyadh Ministry of Economics and Planning.

[26] Ortega, E., Otero, I. and Mancebo, S. (2014), TITIM GIS-tool: A GIS-based decision support system for measuring the territorial impact of transport infrastructures, Expert Systems with Applications, 41 (16) Elsevier. 
دراسة مبنية على نظم المعلومات الجغرافية: العلاقة بين سهولة الوصول إلى الميناء والاقتصاد في المملكة العربية السعودية

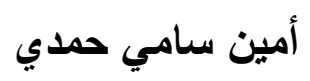

قسم الهندسة المدنبة، كلية الهندسة، جامعة الملك عبد العزيز، جلة 1019 r ، المعلكة العربية السعودية

ahamdi@kau.edu.sa

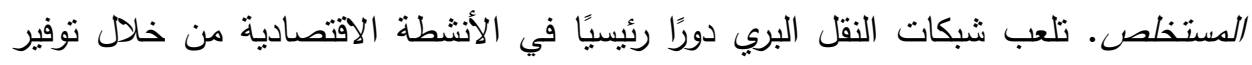
إمكانية الوصول إلى الصناعات والمراكز التجارية. كجزء لا يتجزأ من موانئ نظام النقل. توفر الترات شبكات النقل التبادل الضروري بين الاتصالات البحرية والبرية لتسهيل التفاعل مع المراكز الاقتصادية العالمية. وعادة ما تحدد إمكانية الوصول من المنطقة إلى الميناء قدرتها على الصى

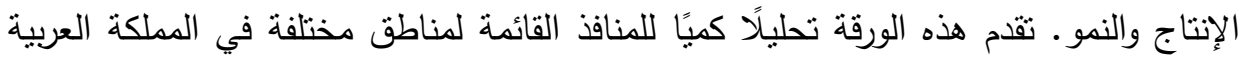

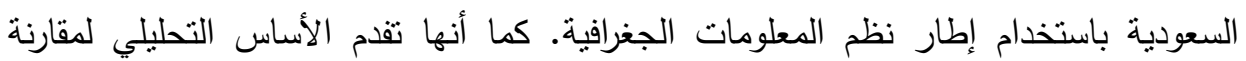
الآتار الجغرافية النسبية للموانئ في سياق الناتج المحلي الإجمالي الإقليمي والتركيز السكاني.

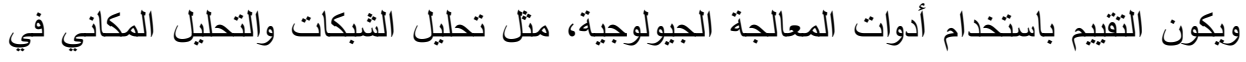
إطار ArcGIS، وكذلك ملامح إمكانية الوصول؛ ثُ يتم تطوير المؤشرات المكانية لقياس التفاعل

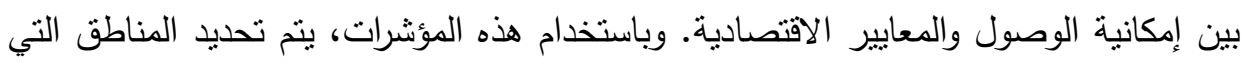
تفنتر إلى إمكانية الوصول المناسبة إلى الميناء. يكثف المزيد من التحليل أن الاستثمار لتحسين

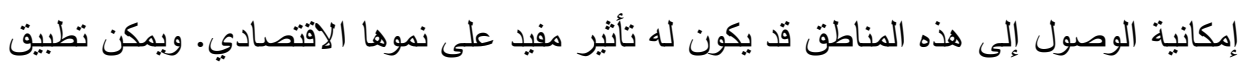
الإجراء المقترح في التخطيط الإقليمي ودراسات الجدوى الاقتصادية. كلمات مفتاحبة: ميناء، سهولة الوصول، الاقتصاد، نظم المعلومات الجغرافية، شبكة. 
